\title{
High mitochondrial content is associated with breast cancer aggressiveness
}

\author{
PATRICK LEBOK $^{1 *}$, KATHARINA SCHÜTT ${ }^{1 *}$, MARTINA KLUTH ${ }^{1}$, ISABELL WITZEL ${ }^{2}$, \\ LINN WÖLBER ${ }^{2}$, PETER PALUCHOWSKI ${ }^{3}$, LUIGI TERRACCIANO ${ }^{4}$, CHRISTIAN WILKE $^{5}$, \\ UWE HEILENKÖTTER ${ }^{6}$, VOLKMAR MÜLLER ${ }^{2}$, BARBARA SCHMALFELDT $^{2}$, \\ RONALD SIMON $^{1}$, GUIDO SAUTER $^{1}$, INGO VON LEFFERN $^{7}$, TILL KRECH $^{8}$, \\ RAINER HORST KRECH ${ }^{8}$, FRANK JACOBSEN ${ }^{1}$ and EIKE BURANDT ${ }^{1}$
}

\author{
${ }^{1}$ Institute of Pathology and ${ }^{2}$ Department of Gynecology, University Medical Center Hamburg-Eppendorf, \\ D-20246 Hamburg; ${ }^{3}$ Department of Gynecology, Regio Clinic Pinneberg, D-25421 Pinneberg, Germany; \\ ${ }^{4}$ Department of Pathology, Basel University Clinics, 4031 Basel, Switzerland; ${ }^{5}$ Department of Gynecology, \\ Regio Clinic Elmshorn, D-25337 Elmshorn; ${ }^{6}$ Department of Gynecology, Clinical Centre Itzehoe, \\ D-25524 Itzehoe; ${ }^{7}$ Department of Gynecology, Albertinen Clinic Schnelsen, D-22457 Hamburg; \\ ${ }^{8}$ Institute of Pathology, Clinical Centre Osnabrück, D-49076 Osnabrück, Germany
}

Received January 13, 2020; Accepted June 23, 2021

DOI: $10.3892 / \mathrm{mco} .2021 .2365$

\begin{abstract}
Mitochondria are relevant for cancer initiation and progression. Antibodies against mitochondrially encoded cytochrome $c$ oxidase II (MTCO2), targeting a mitochondria specific epitope, can be used to quantitate the mitochondria content of tumor cells. The present study evaluated the impact of the cellular mitochondrial content on the prognosis of patients with breast cancer using immunohistochemical analysis on 2,197 arrayed breast cancer specimens. Results were compared with histological tumor parameters, patient overall survival, tumor cell proliferation using Ki67 labeling index (Ki67LI) and various other molecular features. Tumor cells exhibited stronger MTCO2 expression than normal breast epithelial cells. MTCO2 immunostaining was largely absent in normal breast epithelium, but was observed in $71.9 \%$ of 1,797 analyzable cancer specimens, including $34.6 \%$ tumors with weak expression, $22.3 \%$ with moderate expression and $15.0 \%$ with strong expression. High MTCO2 expression
\end{abstract}

Correspondence to: Dr Ronald Simon, Institute of Pathology, University Medical Center Hamburg-Eppendorf, Martinistrasse 52, D-20246 Hamburg, Germany

E-mail:r.simon@uke.de

*Contributed equally

Abbreviations: IHC, immunohistochemistry; Ki67LI, Ki67 labeling index; TMA, tissue microarray; MTCO2, mitochondrially encoded cytochrome $c$ oxidase II

Key words: MTCO2, IHC, TMA, prognosis, breast cancer was significantly associated with advanced tumor stage, high Bloom-Richardson-Elston/Nottingham (BRE) grade, nodal metastasis and shorter overall survival $(\mathrm{P}<0.0001$ each). In multivariate analysis, MTCO2 expression did not provide prognostic information independent of BRE grade, pathological tumor and pathological lymph node status. Additionally, significant associations were observed for high MTCO2 expression and various molecular features, including high Ki67LI, amplifications of HER2, MYC, CCND1 and MDM2, deletions of PTEN, 8p21 and 9p, low estrogen receptor expression $(\mathrm{P}<0.0001 \mathrm{each})$ and progesterone receptor expression $(\mathrm{P}<0.0001)$. The present study demonstrated that high MTCO2 expression was strongly associated with a poor prognosis and unfavorable phenotypical and molecular tumor features in patients with breast cancer. This suggests that the mitochondrial content may have a pivotal role in breast cancer progression.

\section{Introduction}

Breast cancer, the most common malignancy in women (1), is treated by surgical removal of the cancer. In addition, adjuvant systemic therapy is given depending on the perceived aggressiveness of the removed cancer. Currently the established prognostic parameter include histological grade, tumor size, presence of lymph node metastasis, tumor cell proliferation (Ki67 labeling index; Ki67LI) as well as hormonal receptor and HER2 status (2-4) (Ki67) (5). In many patients, supplementary molecular parameters are analyzed (6-8). These molecular classifiers are built on multiplexed analysis of the mRNAs of 21-70 genes (9-11).

The rising interest in mitochondrial function and dysfunction on cancer development has been reviewed by Davis and Williams and Hsu et al $(12,13)$. The loss of proliferation control in cancer cells may result in cellular 
masses that extend beyond the capacity of the supporting vasculature, leading to oxygen and nutrient deprivation. Hence, tumor cells must adapt to overcome these restrictions. Mitochondria are key organelles for energy production in normal and neoplastic cells. Quantity and activity of mitochondria are essential for tumor growth (reviewed in refs. 12-16). Mutations in mitochondrial genes or aberrant mitochondrial content have been described to occur in various cancer types (17-20). An increased mitochondria quantity has earlier been linked to aggressive tumor phenotype and poor prognosis in lung (21), colorectal $(22,23)$, prostate $(24)$, gastric (25), cervical (18), and ovarian cancer (26). In glioma, however, high mitochondria content was linked to favorable prognosis (27). In one study, on 76 breast carcinomas, a prognostic impact of the mitochondria count was also suggested (28). Focused on these reports, we assumed that the cellular mitochondria content of breast cancer cells might potentially be clinically relevant in breast cancer.

The mitochondrially encoded cytochrome $c$ oxidase II (MTCO2) monoclonal antibody recognizes a $60 \mathrm{kDa}$ non-glycosylated protein subunit of cytochrome $c$ oxidase in mitochondria found in human cells and has been used to reveal the mitochondrial content of tumor cells in previous studies $(24,28,29)$. We tested the clinical relevance of the cellular mitochondria content in breast cancer on a pre-existing breast cancer tissue microarray (TMA) containing more than 2,000 cancers. The data show that a 'mitochondrion-rich phenotype' represents a strong and independent predictor of patient prognosis in breast cancer.

\section{Materials and methods}

Patients. A total of 2,197 human breast cancer samples from paraffin-embedded tissue specimens fixed in $4 \%$ neutral buffered formalin were used (30). The breast cancer samples were consecutively collected between 1984 and 2000 and follow-up data were retrospectively collected. The median patient's age was 63 (range, 25-101) years. Overall survival data were available from 1,982 patients (713 patients with and 1,508 without event). The mean follow-up time was 63 months (range, 1-176 months). The TMA was produced as detailed earlier in (31). In short, from each patient one $0.6 \mathrm{~mm}$ core was taken from a representative cancer tissue block. All tissues were distributed among 6 TMA blocks, each containing 263-522 tumor samples. Four-micrometre sections of the TMA blocks were transferred to an adhesive coated slide system (Instrumedics Inc.) for immunohistochemistry (IHC) analysis. Molecular data used in this study were available from previously published studies. These included amplification/deletion data obtained by fluorescence in situ hybridization for HER2, MYC, 8p21, 9p21, and PTEN, as well as $\mathrm{Ki67LI}(30,32-34)$.

IHC. Freshly cut TMA sections were processed the same day. Slides were deparaffinized and exposed to heat-induced antigen retrieval for $5 \mathrm{~min}$ at $121^{\circ} \mathrm{C}$ in $\mathrm{pH} 7.8$ Tris-EDTA-Citrate buffer prior to incubation with the mouse monoclonal antibody MTCO2 (Abcam; \#ab3298; 1/450 dilution). Bound antibody was visualized using the EnVision kit (Dako). MTCO2 staining was homogenous in the analyzed tissue samples and staining intensity of all cases was semiquantitatively assessed in four categories: Negative (no visible staining), weak (1+ staining intensity), moderate $(2+$ stainong intensity) and strong (3+ staining intensity).

Statistical analysis. Contingency tables were calculated to study associations between MTCO2 expression and clinicopathological variables, and the chi-square (likelihood) test was used to find significant relationships. Analysis of variance and F-test was applied to find associations between MTCO2 staining levels and tumor cell proliferation as measured by the Ki67LI. Kaplan-Meier curves were generated using overall survival as the clinical endpoint. The log-rank test was applied to test the significance of differences between stratified survival functions. Cox proportional hazards regression analysis was performed to test the statistical independence and significance between pathological and molecular variables. JMP 12.0 software (SAS Institute Inc.) was used.

\section{Results}

Technical issues. A total of 1,797 (81.8\%) of the 2,197 arrayed tumor samples were interpretable in our TMA analysis. Non-informative cases (400 spots; $18.2 \%$ ) were due to missing tissue samples or the absence of unequivocal cancer tissue in the TMA spot.

MTCO2 immunostaining in normal breast tissue and breast cancer. There were 20 normal breast tissue samples included in our TMA. Normal breast tissues showed negative to moderate MTCO2 staining in luminal cells under the chosen experimental conditions. In cancer, MTCO2 immunostaining was considered weak in $34.6 \%$, moderate in $22.3 \%$ and strong in $15.0 \%$ of tumors. A total of $506(28.2 \%)$ showed no detectable MTCO2 staining and were categorized as negative. Characteristic images of MTCO2 immunostainings are shown in Fig. 1. The intensity of MTCO2 immunostaining varied between histological breast cancer subtypes (Table I). Strong MTCO2 staining was significantly more common in medullary (27.9\%), papillary $(16.0 \%)$ and cancers of no special type (NST; $16.6 \%$ ) than in lobular $(6.9 \%)$ or tubular carcinomas $(4.9 \%)$. Strong MTCO2 staining was also commonly seen in some of the rare breast cancer subtypes such as in 3 of 13 carcinomas with apocrine differentiation, 17 of 61 carcinomas with medullary features and 2 of 12 glycogen-rich clear cell type carcinomas (Table SI).

Association with tumor phenotype and molecular features. High levels of MTCO2 immunostaining were significantly associated with high pT stage, high BRE grade, estrogen and progesterone receptor negativity as well as HER2 overexpression or amplification $(\mathrm{P}<0.0001$ each, Tables I and II). This was also seen for NST carcinomas $(P \leq 0.01$, Table I). Further analyses with previously described frequent and prognostic relevant molecular features of breast cancers such as HER2 (35), and c-MYC- amplification (32) as well as deletions of 8p21 (34), 9p21 (33), and 10q23 (36) showed 
Table I. Association between MTCO2 staining and breast cancer phenotype.

\begin{tabular}{|c|c|c|c|c|c|c|}
\hline \multirow[b]{2}{*}{ Characteristics } & \multirow[b]{2}{*}{$\mathrm{N}$} & \multicolumn{4}{|c|}{ MTCO2 staining } & \multirow[b]{2}{*}{ P-value } \\
\hline & & Negative, $\%$ & Weak, \% & Moderate, $\%$ & Strong, \% & \\
\hline All cases & 1,797 & 28.2 & 34.6 & 22.3 & 15.0 & \\
\hline \multicolumn{7}{|l|}{ Histology } \\
\hline NST & 1,281 & 24.2 & 36.0 & 23.2 & 16.6 & \\
\hline Lobular carcinoma & 233 & 46.4 & 33.1 & 13.7 & 6.9 & $<0.0001^{\mathrm{a}}$ \\
\hline Medullary carcinoma & 61 & 18.0 & 26.2 & 27.9 & 27.9 & $0.0761^{\mathrm{a}}$ \\
\hline Cribriform carcinoma & 55 & 34.6 & 27.3 & 21.8 & 16.4 & $0.3461^{\mathrm{a}}$ \\
\hline Mucinous carcinoma & 51 & 45.1 & 33.3 & 19.6 & 2.0 & $0.0005^{\mathrm{a}}$ \\
\hline Tubular carcinoma & 41 & 48.8 & 39.0 & 7.3 & 4.9 & $0.0004^{\mathrm{a}}$ \\
\hline Papillary carcinoma & 25 & 20.0 & 28.0 & 36.0 & 16.0 & $0.5425^{\mathrm{a}}$ \\
\hline Apocrine carcinoma & 13 & 23.1 & 15.4 & 38.5 & 23.1 & $0.3460^{\mathrm{a}}$ \\
\hline Other rare types ${ }^{b}$ & 22 & 9.1 & 27.3 & 50.0 & 13.6 & $0.0399^{\mathrm{a}}$ \\
\hline \multicolumn{7}{|l|}{ pT stage } \\
\hline pT1 & 631 & 36.3 & 40.3 & 17.6 & 5.9 & $<0.0001\left(<0.0001^{c}\right)$ \\
\hline pT2 & 851 & 24.2 & 32.1 & 24.7 & 19.0 & \\
\hline pT3 & 98 & 25.5 & 30.6 & 24.5 & 19.4 & \\
\hline pT4 & 209 & 21.1 & 30.1 & 24.9 & 23.9 & \\
\hline \multicolumn{7}{|l|}{ BRE grade } \\
\hline G1 & 423 & 41.6 & 37.8 & 13.5 & 7.1 & $<0.0001\left(<0.0001^{c}\right)$ \\
\hline G2 & 673 & 29.9 & 35.5 & 23.5 & 11.1 & \\
\hline G3 & 564 & 15.4 & 26.6 & 29.6 & 28.4 & \\
\hline \multicolumn{7}{|l|}{ Nodal stage } \\
\hline $\mathrm{pNO}$ & 761 & 33.5 & 34.2 & 22.7 & 9.6 & $<0.0001\left(0.0063^{c}\right)$ \\
\hline $\mathrm{pN} 1$ & 644 & 25.6 & 36.2 & 20.3 & 17.9 & \\
\hline $\mathrm{pN} 2$ & 103 & 18.5 & 38.8 & 24.3 & 18.5 & \\
\hline $\mathrm{pN} 3$ & 0 & 0.0 & 0.0 & 0.0 & 0.0 & \\
\hline \multicolumn{7}{|l|}{ Estrogen receptor } \\
\hline Negative & 406 & 16.01 & 29.31 & 28.82 & 25.86 & $<0.0001\left(<0.0001^{\mathrm{c}}\right)$ \\
\hline Positive & 1,296 & 31.33 & 36.5 & 20.45 & 11.73 & \\
\hline \multicolumn{7}{|l|}{ Progesterone receptor } \\
\hline Negative & 1,059 & 29.27 & 32.01 & 22.95 & 15.77 & $<0.0001\left(0.0795^{c}\right)$ \\
\hline Positive & 569 & 26.19 & 40.07 & 19.68 & 14.06 & \\
\hline
\end{tabular}

${ }^{\mathrm{a}}$ Vs. NST; ${ }^{\mathrm{b}}$ Other types included adenoid-cystic carcinoma, carcinoma with apocrine differentiation, carcinoma with medullary features, carcinoma with neuroendocrine features, carcinoma with signet-ring-cell differentiation, glycogen-rich clear cell carcinoma, metaplastic carcinoma of NST and lipid-rich carcinoma; 'in NST only. Numbers do not always add up to 1,797 in the different categories due to cases with missing data. NST, no special type; pT, pathological tumor; pN, pathological lymph node; MTCO2, mitochondrially encoded cytochrome c oxidase II; BRE, Bloom-Richardson-Elston/Nottingham system.

significant associations with high MTCO2 staining intensity (Table II).

Association with tumor cell proliferation. Data on tumor cell proliferation as evaluated by the Ki67LI were available from a previous study with the same TMA (30). The mean Ki67LI increased from 19.62 \pm 0.66 in MTCO2 negative cancers to $37.75 \pm 0.93$ in cancers with strong MTCO2 staining $(\mathrm{P}<0.0001)$. This statistically significant relationship was also seen in tumor subsets with identical pT or pN stage, lobular and medullary carcinoma, BRE grade and HER2 status as well as $8 \mathrm{p}$ and PTEN deletion. All data are summarized in Table III.

Prognostic significance of MTCO2 expression. Survival data were available for 1,806 cancers with interpretable IHC results. The rate of surviving patients continuously decreased with increasing levels of MTCO2 immunostaining $(\mathrm{P}=0.0001$; Fig. 2). The association between strong MTCO2 immunostaining and poor prognosis was also seen in the subgroup of NST cancers $(\mathrm{P}<0.0001$; Fig. 2$)$ and in the nodal positive subset $(\mathrm{P}<0.0001$; Fig. 2$)$ and to a much lesser extent 
Table II. Association between MTCO2 staining and molecular alterations.

\begin{tabular}{lcccccr}
\hline & & \multicolumn{5}{c}{ MTCO2 staining } \\
\cline { 3 - 5 } Molecular alterations & $\mathrm{N}$ & Negative, $\%$ & Weak, $\%$ & Moderate, $\%$ & Strong, $\%$ & P-value \\
\hline HER2 normal & 1,141 & 29.2 & 36.3 & 21.2 & 13.3 & $<0.0001$ \\
HER2 amplified & 239 & 15.5 & 32.6 & 30.1 & 21.8 & \\
MYC normal & 1,232 & 26.9 & 34.9 & 23.1 & 15.1 & $<0.0001$ \\
MYC amplified & 64 & 7.8 & 29.7 & 28.1 & 34.4 & \\
8p21 normal & 578 & 27.7 & 39.1 & 20.9 & 12.3 & $<0.0001$ \\
8p21 deletion & 553 & 17.0 & 27.7 & 29.5 & 25.9 & 0.0182 \\
9p21 normal & 835 & 25.0 & 33.1 & 24.4 & 17.5 & \\
9p21 deletion & 150 & 16.7 & 28.0 & 32.0 & 23.3 & $<0.0001$ \\
10q23 normal & 904 & 25.0 & 35.0 & 22.9 & 17.1 & $<$ \\
10q23 deletion & 216 & 11.6 & 26.4 & 36.1 & 25.9 & \\
\hline
\end{tabular}

MTCO2, mitochondrially encoded cytochrome $c$ oxidase II.

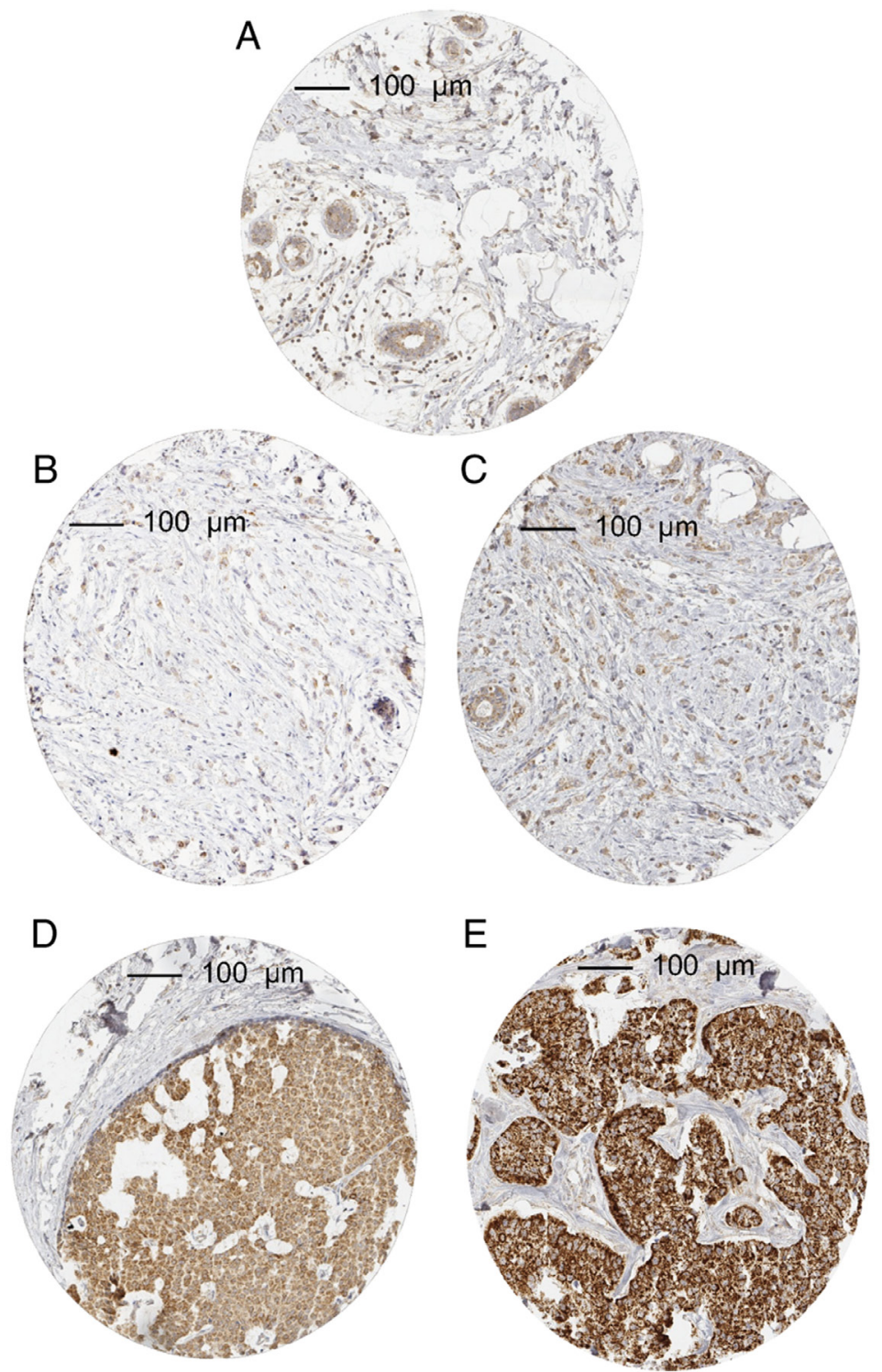

Figure 1. Representative images of MTCO2 staining in breast cancer tissues. (A) Normal breast tissue, (B) negative staining in breast cancer tissue, (C) weak staining in breast cancer tissue, (D) moderate staining in breast cancer tissue and (E) strong staining in breast cancer tissue. Scale bar, $100 \mu \mathrm{m}$. MTCO2, mitochondrially encoded cytochrome $c$ oxidase II. 
Table III. Association between MTCO2 staining and Ki67LI.

\begin{tabular}{|c|c|c|c|c|}
\hline Cases & MTCO2 staining & $\mathrm{N}$ & Ki67LI & P-value \\
\hline \multirow[t]{4}{*}{ All cases } & Negative & 428 & $19.6 \pm 0.7$ & $<0.0001$ \\
\hline & Weak & 523 & $27.0 \pm 0.6$ & \\
\hline & Moderate & 338 & $33.0 \pm 0.8$ & \\
\hline & Strong & 216 & $37.8 \pm 0.9$ & \\
\hline \multirow[t]{4}{*}{ No special type } & Negative & 264 & $20.7 \pm 0.8$ & $<0.0001$ \\
\hline & Weak & 383 & $27.8 \pm 0.7$ & \\
\hline & Moderate & 253 & $33.3 \pm 0.9$ & \\
\hline & Strong & 168 & $38.0 \pm 1.1$ & \\
\hline \multirow[t]{4}{*}{ Lobular cancer } & Negative & 92 & $16.2 \pm 1.2$ & $<0.0001$ \\
\hline & Weak & 66 & $20.3 \pm 1.4$ & \\
\hline & Moderate & 24 & $28.4 \pm 2.3$ & \\
\hline & Strong & 15 & $26.9 \pm 2.9$ & \\
\hline \multirow[t]{4}{*}{ Medullary cancer } & Negative & 9 & $29.9 \pm 5.2$ & 0.0109 \\
\hline & Weak & 15 & $43.7 \pm 4.1$ & \\
\hline & Moderate & 16 & $50.2 \pm 3.9$ & \\
\hline & Strong & 15 & $50.9 \pm 4.0$ & \\
\hline \multirow[t]{4}{*}{ HER2 amplified } & Negative & 32 & $26.7 \pm 2.3$ & $<0.0001$ \\
\hline & Weak & 67 & $34.2 \pm 1.6$ & \\
\hline & Moderate & 64 & $40.3 \pm 1.6$ & \\
\hline & Strong & 43 & $41.3 \pm 1.9$ & \\
\hline \multirow[t]{4}{*}{ MYC amplified } & Negative & 4 & $28.5 \pm 7.4$ & 0.3927 \\
\hline & Weak & 19 & $38.3 \pm 3.4$ & \\
\hline & Moderate & 17 & $41.6 \pm 3.6$ & \\
\hline & Strong & 21 & $41.6 \pm 3.2$ & \\
\hline \multirow[t]{4}{*}{$8 \mathrm{p}$ deletion } & Negative & 86 & $24.8 \pm 1.5$ & $<0.0001$ \\
\hline & Weak & 135 & $30.2 \pm 1.2$ & \\
\hline & Moderate & 145 & $35.3 \pm 1.2$ & \\
\hline & Strong & 116 & $40.3 \pm 1.3$ & \\
\hline \multirow[t]{4}{*}{ PTEN deletion } & Negative & 24 & $30.6 \pm 3.2$ & 0.0118 \\
\hline & Weak & 55 & $37.7 \pm 2.1$ & \\
\hline & Moderate & 75 & $41.7 \pm 1.8$ & \\
\hline & Strong & 44 & $42.2 \pm 2.3$ & \\
\hline \multirow[t]{4}{*}{ pT1 } & Negative & 192 & $19.0 \pm 0.9$ & $<0.0001$ \\
\hline & Weak & 200 & $23.8 \pm 0.9$ & \\
\hline & Moderate & 90 & $29.9 \pm 1.3$ & \\
\hline & Strong & 31 & $37.8 \pm 2.3$ & \\
\hline \multirow[t]{4}{*}{ pT2 } & Negative & 170 & $19.9 \pm 1.1$ & $<0.0001$ \\
\hline & Weak & 238 & $29.6 \pm 0.9$ & \\
\hline & Moderate & 179 & $35.3 \pm 1.1$ & \\
\hline & Strong & 127 & $37.9 \pm 1.3$ & \\
\hline \multirow[t]{4}{*}{ pT3 } & Negative & 23 & $18.2 \pm 3.1$ & $<0.0001$ \\
\hline & Weak & 27 & $31.2 \pm 2.9$ & \\
\hline & Moderate & 22 & $30.1 \pm 3.2$ & \\
\hline & Strong & 16 & $43.8 \pm 3.7$ & \\
\hline \multirow[t]{4}{*}{ pT4 } & Negative & 41 & $21.9 \pm 2.2$ & $<0.0001$ \\
\hline & Weak & 57 & $25.3 \pm 1.7$ & \\
\hline & Moderate & 44 & $31.9 \pm 1.9$ & \\
\hline & Strong & 41 & $34.9 \pm 2.1$ & \\
\hline \multirow{4}{*}{ BRE G1 } & Negative & 150 & $15.5 \pm 0.8$ & $<0.0001$ \\
\hline & Weak & 127 & $19.5 \pm 0.9$ & \\
\hline & Moderate & 45 & $21.4 \pm 1.5$ & \\
\hline & Strong & 25 & $26.4 \pm 1.9$ & \\
\hline \multirow[t]{4}{*}{ BRE G2 } & Negative & 170 & $18.8 \pm 0.9$ & $<0.0001$ \\
\hline & Weak & 208 & $23.7 \pm 0.8$ & \\
\hline & Moderate & 134 & $28.9 \pm 01.0$ & \\
\hline & Strong & 63 & $31.4 \pm 1.4$ & \\
\hline
\end{tabular}


Table III. Continued.

\begin{tabular}{llrl}
\hline Cases & MTCO2 staining & $\mathrm{N}$ & Ki67LI \\
\hline BRE G3 & Negative & 76 & $29.4 \pm 1.7$ \\
& Weak & 130 & $37.5 \pm 1.3$ \\
& Moderate & 145 & $40.4 \pm 1.2$ \\
& Strong & 124 & $43.2 \pm 1.3$ \\
$\mathrm{pN} 0$ & Negative & 219 & $19.5 \pm 0.9$ \\
& Weak & 216 & $26.5 \pm 0.9$ \\
& Moderate & 144 & $34.5 \pm 1.1$ \\
& Strong & 59 & $38.9 \pm 1.8$ \\
$\mathrm{pN1}$ & Negative & 138 & $19.4 \pm 1.2$ \\
& Weak & 198 & $27.3 \pm 1.0$ \\
& Moderate & 111 & $32.2 \pm 1.3$ \\
$\mathrm{pN} 2$ & Strong & 92 & $39.1 \pm 1.4$ \\
& Negative & 18 & $25.6 \pm 3.2$ \\
& Weak & 34 & $29.4 \pm 2.3$ \\
& Moderate & 23 & $33.4 \pm 2.8$ \\
& Strong & 16 & $41.4 \pm 3.4$
\end{tabular}

Ki67LI, Ki67 labeling index; pT, pathological tumor; pN, pathological lymph node; MTCO2, mitochondrially encoded cytochrome $c$ oxidase II; G, grade; BRE, Bloom-Richardson-Elston/Nottingham system.
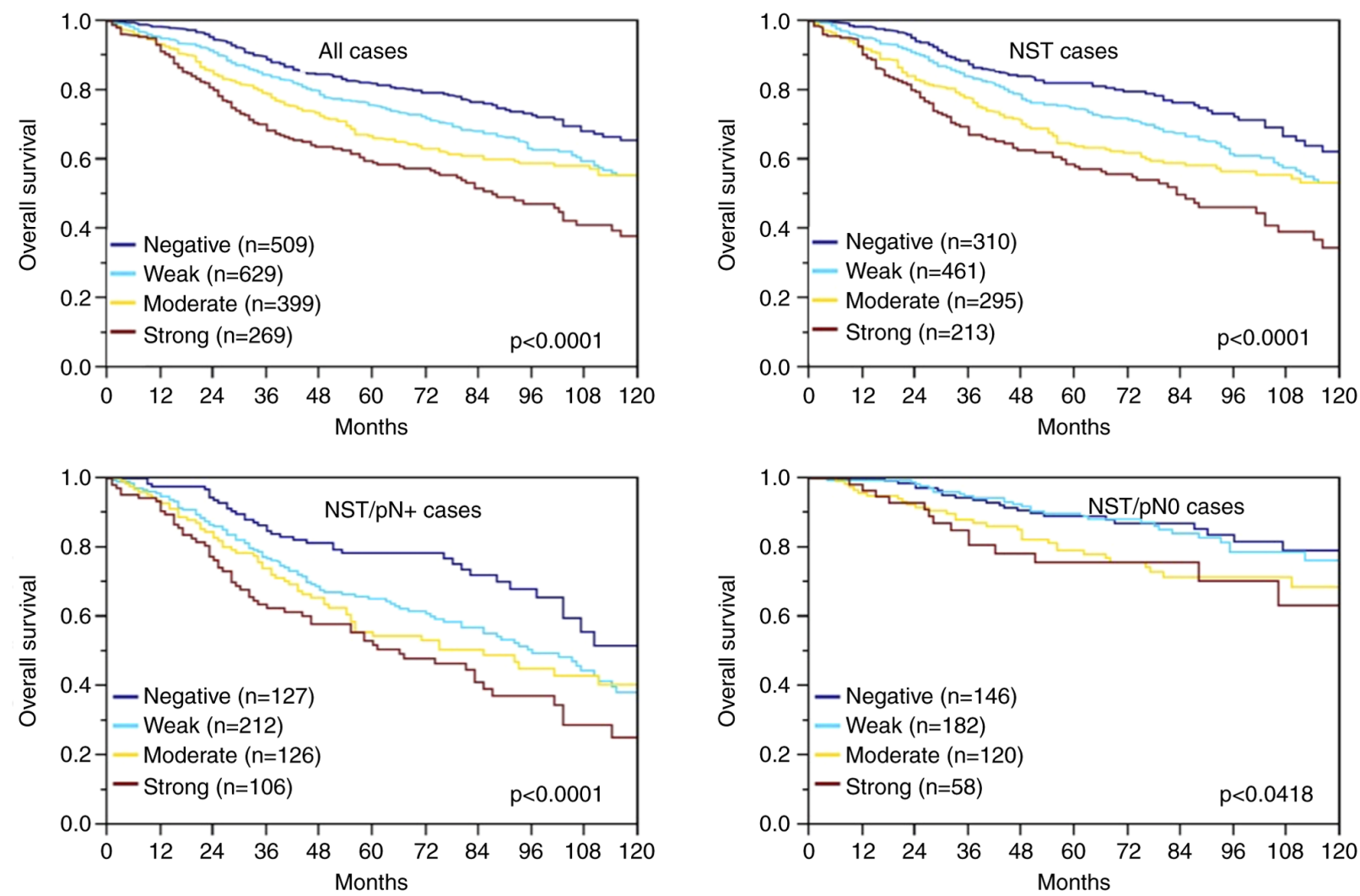

Figure 2. Association between MTCO2 staining and overall survival. MTCO2, mitochondrially encoded cytochrome c oxidase II; NST, no special type; pN, pathological lymph node.

also in nodal negative NST cancers ( $\mathrm{P}=0.0418$; Fig. 2). Multivariate analysis for NST cancers including pT stage, nodal status, and BRE grade did not identify MTCO2 immunostaining as an independent prognosticator of survival, however (Table IV).

\section{Discussion}

Our study shows that high mitochondria content is significantly linked to disadvantageous tumor phenotype and bad prognosis in breast cancer. 
Table IV. Multivariate analysis in all breast cancer cases $(\mathrm{n}=1,377)$.

\begin{tabular}{lccc}
\hline Characteristics & $\begin{array}{c}\text { Hazard } \\
\text { ratio }\end{array}$ & P-value & Overall P-value \\
\hline pT stage & & & \\
2 vs. 1 & 1.52 & 0.0010 & $<0.0001$ \\
3 vs. 2 & 1.05 & 0.7700 & \\
4 vs. 2 & 1.65 & 0.0006 & \\
4 vs. 3 & 1.56 & 0.2230 & \\
BRE grade & & & $<0.0001$ \\
G2 vs. G1 & 1.35 & 0.0522 & \\
G3 vs. G1 & 2.81 & $<0.0001$ & \\
G3 vs. G2 & 2.08 & $<0.0001$ & \\
pN & & & $<0.0001$ \\
1 vs. 0 & 2.26 & $<0.0001$ & \\
2 vs. 1 & 2.33 & $<0.0001$ & \\
2 vs. 0 & 5.27 & $<0.0001$ & \\
MTCO2 staining & & & 0.1464 \\
Weak vs. negative & 1.33 & 0.0396 & \\
Moderate vs. weak & 1.01 & 0.9109 & \\
Strong vs. moderate & 0.88 & 0.4133 & \\
\hline
\end{tabular}

pT, pathological tumor; pN, pathological lymph node; MTCO2, mitochondrially encoded cytochrome $c$ oxidase II; G, grade; BRE, Bloom-Richardson-Elston/Nottingham system.

MTCO2 immunostaining is highly specific for the mitochondrial DNA encoded second subunit of cytochrome $c$ oxidase and can thus be used to quantitate the mitochondria content by IHC (29). Although mitochondria are present in every normal and neoplastic human cell, $28.2 \%$ of our tumors had a negative staining result. This was due to our approach to define experimental conditions, which distinguish cancers with low and high mitochondria quantities. The higher level of MTCO2 immunostaining in breast cancers as compared to normal breast tissues fits with the concept that neoplastic transformation goes along with higher cellular activity requiring more active mitochondria. That a striking further increase of MTCO2 immunostaining was detected with rising tumor grade and stage, demonstrates that elevated numbers of mitochondria are also supporting cancer progression. This is consistent with increasing energy requirement and a rearranged metabolism during tumor progression. Our data fit well with findings in multiple other cancer types, including lung (21), colorectal (22,23), prostate (24), gastric (25), cervical (18), and ovarian cancer (26), where a similar link between high levels of MTCO2 with adverse tumor phenotype and bad prognosis was shown.

In this study, a ubiquitously expressed protein was quantitated by IHC. The TMA approach is optimal for the identification of subtle staining differences of proteins that are abundantly present in cancer, such as mitochondrial components, because TMAs enable maximal experimental standardization at all levels. In our study, more than 1,700 breast cancers were analyzed the same day for maximal standardization. Moreover, all TMA sections were cut on one day immediately before staining in order to avoid unequal decay of a tissues reactivity to antibody binding (37). Finally, one pathologist interpreted all immunostainings in one continuous session to enable maximal standardization of staining interpretation. In earlier studies, this breast cancer TMA enabled us to validate the prognostic impact of several well-established prognostic biomarkers, such as HER 2 alterations, estrogen and progesterone receptor expression (30), high Ki67LI, nuclear p53 accumulation (30), and PTEN deletion (34). These earlier data demonstrate the utility of our patient cohort to identify prognostic biomarkers.

The molecular database that has been collected during earlier studies for our set of cancers offers the advantage that biomarkers of interest can always be compared with preexisting data. For the purpose of this study, we had selected HER2 amplification as well as estrogen and progesterone receptor expression because of their central role in breast cancer. The strong link between MTCO2 expression and these important features further illustrates the importance of the mitochondria quantity in breast cancer. Our analyses also included Ki67LI as another pivotal parameter for cellular activity and various further chromosomal deletions and amplifications because of the role of some of them for regulating mitochondrion homeostasis.

Mitochondrial homeostasis is critical for cancer. A sufficiently high production of mitochondria is required to suffice the needs for energy production and cell metabolism. The prominent association found between c-Myc amplification and high MTCO2 expression fits well with the key role of c-Myc as an activator of mitochondrial biogenesis in cancer (38-40). The transcription factor c-Myc is best known for its critical role in cell cycle regulation, cell growth, metabolism and apoptosis (41-43). However, c-Myc also targets more than 400 different mitochondrial genes $(38-41,44)$. Studies have demonstrated that an elevated or reduced c-Myc protein quantity leads to an increased/diminished mitochondrial mass $(45,46)$. This couples c-Myc's role of a key activator of cell cycle activity with mitochondrial biogenesis. As such, c-Myc increases cellular biosynthetic and respiratory capacity by upregulating mitochondrial metabolism to complement its effects on stimulating cell cycle progression to coordinate rapid cell growth $(45,47)$.

A critical role of high mitochondrion count for cell proliferation in breast cancer is supported by our data showing a striking link between MTCO2 expression and a high Ki67LI which was also visible in the vast majority of groups defined by identical morphological or molecular features.

The PTEN-induced putative kinase 1 (PINK1)/Parkin pathway is a major inducer of mitophagy. It is triggered by mitochondrial membrane depolarization, a signal of mitochondrial dysfunction that results from lack of reducing equivalents, hypoxia and impaired electron transport [reviewed in (48)]. The conspicuous relationship between PTEN deletion and high MTCO2 staining in our study may thus indicate that high mitochondria quantities may also be caused by reduced mitophagy. Although clearance of damaged mitochondria via mitophagy is viewed to be also critical for cellular fitness since dysfunctional mitochondria can impair the electron transport chain function, reduced mitophagy can also promote cancer reviewed in ref. 49). Mitophagy-deficient Parkin null mice develop spontaneous hepatic tumors (50). 
Decreased mitophagy may allow for a permissive threshold of dysfunctional mitochondria to persist, generating increased tumor-promoting free oxygen radicals reviewed in ref. 49).

Cytochrome oxidase subunit 2 is a key enzyme of the respiratory chain, catalyzing electron transfer from NADH and succinate to molecular oxygen (51). It has no direct tumor related function but serves as a marker for the cellular mitochondria content. Increased mitochondria content in cancer cells often occurs as a result of the elevated metabolism and energy needs of expanding tumor cell populations (52). Although the mitochondrial content provided no additional prognostic information in multivariate analysis, the marked prognostic relevance of MTCO2 immunostaining found in this study may still suggest 'mitochondria content' as a biomarker with potential clinical utility. Molecular analyses are frequently done in breast cancer to better assess patient prognosis and to determine whether adjuvant chemotherapy should be applied (6-8). Most currently used tests are analyzing RNAs of multiple genes forming a prognostic score $(9-11,53)$. RNA based tests share the disadvantage, however, that the analyzed RNA always represents a mixture of cancer cells and a variable fraction of non-neoplastic inflammatory and stromal cells. Now that multiplex fluorescent-based quantitative IHC becomes increasingly available, it is well possible that RNA based test will sooner or later be replaced by IHC based multi-gene tests. MTCO 2 might be a candidate for being part of such a test, also because of the general biologic importance of mitochondria, which are also the target of several anti-cancer drugs under development reviewed in refs. 54-57).

It is a limitation of our study that MTCO2 IHC data highlight relevant associations between cancer phenotype and genotype but do not provide mechanistic insights into the putative cancer biological role of MTCO2. Further studies on the tumor relevant aspects of mitochondrial density and MTCO2 protein function are required to better understand the prognostic role of MTCO2 in breast cancer.

In summary, our findings identify MTCO2 immunostaining as a powerful prognostic biomarker in breast cancer. MTCO2 measurement, most likely in combination with other antibodies might be of clinical utility in breast cancer prognosis assessment.

\section{Acknowledgements}

The authors would like to thank Ms. Inge Brandt and Ms. Sünje Seekamp from the Institute of Pathology of University Medical Center Hamburg-Eppendorf (Hamburg, Germany) for excellent technical assistance.

\section{Funding}

No funding was received.

\section{Availability of data and materials}

The datasets used and/or analyzed during the current study are available from the corresponding author on reasonable request.

\section{Authors' contributions}

All authors contributed to the conception and design of the study. PL, KS, MK, IW, LW, PP, LT, CW, UH, VM, BS, IvL,
TK, RHK and FJ prepared the material, and collected and analyzed the data. PL, EB, RS, MK and GS wrote the first draft of the manuscript, and all authors commented on previous versions of the manuscript. RS, MK and GS confirmed the authenticity of all the raw data. All authors read and approved the final manuscript.

\section{Ethics approval and consent to participate}

The usage of archived diagnostic leftover tissues for manufacturing the tissue microarrays and their analysis for research purposes, as well as patient data analysis, has been approved by local laws (HmbKHG, §12) and by the local ethics committee (Ethics Commission of the Ärtzekammer Hamburg, Hamburg, Germany; approval no. WF-049/09). Informed consent was waived by the ethics committee due to the retrospective nature of the study. All work has been carried out in compliance with the Declaration of Helsinki.

\section{Patient consent for publication}

Not applicable.

\section{Competing interests}

The authors declare that they have no competing interests.

\section{References}

1. Siegel RL, Miller KD and Jemal A: Cancer statistics, 2020. CA Cancer J Clin 70: 7-30, 2020.

2. Leong AS and Raymond WA: Prognostic parameters in breast cancer. Pathology 21: 169-175, 1989.

3. Taneja P, Maglic D, Kai F, Zhu S, Kendig RD, Fry EA and Inoue K: Classical and novel prognostic markers for breast cancer and their clinical significance. Clin Med Insights Oncol 4: 15-34, 2010.

4. Soliman NA and Yussif SM: Ki-67 as a prognostic marker according to breast cancer molecular subtype. Cancer Biol Med 13: 496-504, 2016.

5. Cao SS and Lu CT: Recent perspectives of breast cancer prognosis and predictive factors. Oncol Lett 12: 3674-3678, 2016.

6. Giuliano AE, Hunt KK, Ballman KV, Beitsch PD, Whitworth PW, Blumencranz PW, Leitch AM, Saha S, McCall LM and Morrow M: Axillary dissection vs no axillary dissection in women with invasive breast cancer and sentinel node metastasis: A randomized clinical trial. JAMA 305: 569-575, 2011.

7. McVeigh TP, Hughes LM, Miller N, Sheehan M, Keane M, Sweeney KJ and Kerin MJ: The impact of Oncotype DX testing on breast cancer management and chemotherapy prescribing patterns in a tertiary referral centre. Eur J Cancer 50: 2763-2770, 2014.

8. Naoi Y and Noguchi S: Multi-gene classifiers for prediction of recurrence in breast cancer patients. Breast Cancer 23: 12-18, 2016.

9. Hornberger J, Cosler LE and Lyman GH: Economic analysis of targeting chemotherapy using a 21-gene RT-PCR assay in lymph-node-negative, estrogen-receptor-positive, early-stage breast cancer. Am J Manag Care 11: 313-324, 2005.

10. Cobleigh MA, Tabesh B, Bitterman P, Baker J, Cronin M, Liu ML, Borchik R, Mosquera JM, Walker MG and Shak S: Tumor gene expression and prognosis in breast cancer patients with 10 or more positive lymph nodes. Clin Cancer Res 11: 8623-8631, 2005.

11. van 't Veer LJ, Dai H, van de Vijver MJ, He YD, Hart AA, Mao M, Peterse HL, van der Kooy K, Marton MJ, Witteveen AT, et al: Gene expression profiling predicts clinical outcome of breast cancer. Nature 415: 530-536, 2002.

12. Davis RE and Williams M: Mitochondrial function and dysfunction: An update. J Pharmacol Exp Ther 342: 598-607, 2012. 
13. Hsu CC, Tseng LM and Lee HC: Role of mitochondrial dysfunction in cancer progression. Exp Biol Med (Maywood) 241: 1281-1295, 2016.

14. Boland ML, Chourasia AH and Macleod KF: Mitochondrial dysfunction in cancer. Front Oncol 3: 292, 2013.

15. Porporato PE, Filigheddu N, Pedro JMB, Kroemer G and Galluzzi L: Mitochondrial metabolism and cancer. Cell Res 28: 265-280, 2018.

16. Grasso D, Zampieri LX, Capeloa T, Van de Velde JA and Sonveaux P: Mitochondria in cancer. Cell Stress 4: 114-146, 2020

17. Abu-Amero KK, Alzahrani AS, Zou M and Shi Y: High frequency of somatic mitochondrial DNA mutations in human thyroid carcinomas and complex I respiratory defect in thyroid cancer cell lines. Oncogene 24: 1455-1460, 2005.

18. Warowicka A, Kwasniewska A and Gozdzicka-Jozefiak A: Alterations in mtDNA: A qualitative and quantitative study associated with cervical cancer development. Gynecol Oncol 129: 193-198, 2013

19. Gao JY, Song BR, Peng JJ and Lu YM: Correlation between mitochondrial TRAP-1 expression and lymph node metastasis in colorectal cancer. World J Gastroenterol 18: 5965-5971, 2012.

20. Qian XL, Li YQ, Gu F, Liu FF, Li WD, Zhang XM and Fu L: Overexpression of ubiquitous mitochondrial creatine kinase (uMtCK) accelerates tumor growth by inhibiting apoptosis of breast cancer cells and is associated with a poor prognosis in breast cancer patients. Biochem Biophys Res Commun 427: 60-66, 2012.

21. Sotgia F and Lisanti MP: Mitochondrial markers predict survival and progression in non-small cell lung cancer (NSCLC) patients: Use as companion diagnostics. Oncotarget 8: 68095-68107, 2017.

22. Ambrosini-Spaltro A, Salvi F, Betts CM, Frezza GP Piemontese A, Del Prete P, Baldoni C, Foschini MP and Viale G: Oncocytic modifications in rectal adenocarcinomas after radio and chemotherapy. Virchows Arch 448: 442-448, 2006.

23. Wang Y, He S, Zhu X, Qiao W and Zhang J: High copy number of mitochondrial DNA predicts poor prognosis in patients with advanced stage colon cancer. Int J Biol Markers 31: e382-e388, 2016

24. Grupp K, Jedrzejewska K, Tsourlakis MC, Koop C, Wilczak W, Adam M, Quaas A, Sauter G, Simon R, Izbicki JR, et al: High mitochondria content is associated with prostate cancer disease progression. Mol Cancer 12: 145, 2013.

25. Sotgia F and Lisanti MP: Mitochondrial biomarkers predict tumor progression and poor overall survival in gastric cancers: Companion diagnostics for personalized medicine. Oncotarget 8 : 67117-67128, 2017.

26. Hu B and Guo Y: Inhibition of mitochondrial translation as a therapeutic strategy for human ovarian cancer to overcome chemoresistance. Biochem Biophys Res Commun 509: 373-378, 2019.

27. Zhang Y, Qu Y, Gao K, Yang Q, Shi B, Hou P and Ji M: High copy number of mitochondrial DNA (mtDNA) predicts good prognosis in glioma patients. Am J Cancer Res 5: 1207-1216, 2015.

28. Ragazzi M, de Biase D, Betts CM, Farnedi A, Ramadan SS Tallini G, Reis-Filho JS and Eusebi V: Oncocytic carcinoma of the breast: Frequency, morphology and follow-up. Hum Pathol 42: 166-175, 2011.

29. Williams SL, Valnot I, Rustin P and Taanman JW: Cytochrome c oxidase subassemblies in fibroblast cultures from patients carrying mutations in COX10, SCO1, or SURF1. J Biol Chem 279: 7462-7469, 2004

30. Ruiz C, Seibt S, Al Kuraya K, Siraj AK, Mirlacher M, Schraml P, Maurer R, Spichtin H, Torhorst J, Popovska S, et al: Tissue microarrays for comparing molecular features with proliferation activity in breast cancer. Int J Cancer 118: 2190-2194, 2006.

31. Mirlacher M and Simon R: Recipient block TMA technique. Methods Mol Biol 664: 37-44, 2010.

32. Al-Kuraya K, Schraml P, Torhorst J, Tapia C, Zaharieva B, Novotny H, Spichtin H, Maurer R, Mirlacher M, Köchli O, et al: Prognostic relevance of gene amplifications and coamplifications in breast cancer. Cancer Res 64: 8534-8540, 2004.

33. Lebok P, Roming M, Kluth M, Koop C, Özden C, Taskin B, Hussein K, Lebeau A, Witzel I, Wölber L, et al: p16 overexpression and 9p21 deletion are linked to unfavorable tumor phenotype in breast cancer. Oncotarget 7: 81322-81331, 2016

34. Lebok P, Mittenzwei A, Kluth M, Özden C, Taskin B, Hussein K, Möller K, Hartmann A, Lebeau A, Witzel I, et al: 8p deletion is strongly linked to poor prognosis in breast cancer. Cancer Biol Ther 16: 1080-1087, 2015.

35. Yan M, Schwaederle M, Arguello D, Millis SZ, Gatalica Z and Kurzrock R: HER2 expression status in diverse cancers: Review of results from 37,992 patients. Cancer Metastasis Rev 34: $157-164,2015$.
36. Lebok P, Kopperschmidt V, Kluth M, Hube-Magg C, Özden C, B T, Hussein K, Mittenzwei A, Lebeau A, Witzel I, et al: Partial PTEN deletion is linked to poor prognosis in breast cancer. BMC Cancer 15: 963-910, 2015.

37. Simon R, Mirlacher M and Sauter G: Immunohistochemical analysis of tissue microarrays. Methods Mol Biol 664: 113-126, 2010.

38. Nieminen AI, Partanen JI, Hau A and Klefstrom J: c-Myc primed mitochondria determine cellular sensitivity to TRAIL-induced apoptosis. EMBO J 26: 1055-1067, 2007.

39. Desbiens KM, Deschesnes RG, Labrie MM, Desfossés Y, Lambert H, Landry J and Bellmann K: c-Myc potentiates the mitochondrial pathway of apoptosis by acting upstream of apoptosis signal-regulating kinase 1 (Ask1) in the p38 signalling cascade. Biochem J 372: 631-641, 2003.

40. Klefstrom J, Verschuren E and Evan G: c-Myc augments the apoptotic activity of cytosolic death receptor signaling proteins by engaging the mitochondrial apoptotic pathway. J Biol Chem 277: 43224-43232, 2002.

41. Dang CV, O'Donnell KA, Zeller KI, Nguyen T, Osthus RC and Li F: The c-Myc target gene network. Semin Cancer Biol 16: 253-264, 2006

42. Amati B, Frank SR, Donjerkovic D and Taubert S: Function of the c-Myc oncoprotein in chromatin remodeling and transcription. Biochim Biophys Acta 1471: M135-M145, 2001.

43. Dang CV, Resar LM, Emison E, Kim S, Li Q, Prescott JE, Wonsey D and Zeller K: Function of the c-Myc oncogenic transcription factor. Exp Cell Res 253: 63-77, 1999.

44. Wonsey DR, Zeller KI and Dang CV: The c-Myc target gene PRDX 3 is required for mitochondrial homeostasis and neoplastic transformation. Proc Natl Acad Sci USA 99: 6649-6654, 2002.

45. Li F, Wang Y, Zeller KI, Potter JJ, Wonsey DR, O'Donnell KA, Kim JW, Yustein JT, Lee LA and Dang CV: Myc stimulates nuclearly encoded mitochondrial genes and mitochondrial biogenesis. Mol Cell Biol 25: 6225-6234, 2005.

46. Graves JA, Wang Y, Sims-Lucas S, Cherok E, Rothermund K, Branca MF, Elster J, Beer-Stolz D, Van Houten B, Vockley J and Prochownik EV: Mitochondrial structure, function and dynamics are temporally controlled by c-Myc. PLoS One 7: e37699, 2012.

47. Miller DM, Thomas SD, Islam A, Muench D and Sedoris K: c-Myc and cancer metabolism. Clin Cancer Res 18: 5546-5553, 2012.

48. Leites EP and Morais VA: Mitochondrial quality control pathways: PINK1 acts as a gatekeeper. Biochem Biophys Res Commun 500: 45-50, 2018.

49. Panigrahi DP, Praharaj PP, Bhol CS, Mahapatra KK, Patra S, Behera BP, Mishra SR and Bhutia SK: The emerging, multifaceted role of mitophagy in cancer and cancer therapeutics. Semin Cancer Biol 66: 45-58, 2020.

50. Wang H, Ni HM, Chao X, Ma X, Rodriguez YA, Chavan H, Wang S, Krishnamurthy P, Dobrowsky R, Xu DX, et al: Double deletion of PINK1 and Parkin impairs hepatic mitophagy and exacerbates acetaminophen-induced liver injury in mice. Redox Biol 22: 101148, 2019.

51. Rak M, Bénit P, Chrétien D, Bouchereau J, Schiff M,El-Khoury R, Tzagoloff A and Rustin P: Mitochondrial cytochrome $c$ oxidase deficiency. Clin Sci (Lond) 130: 393-407, 2016.

52. Gundamaraju R, Lu W and Manikam R: Revisiting Mitochondria Scored Cancer Progression and Metastasis. Cancers (Basel) 13: 432, 2021.

53. Vieira AF and Schmitt F: An update on breast cancer multigene prognostic tests-emergent clinical biomarkers. Front Med (Lausanne) 5: 248, 2018

54. Gogvadze V, Orrenius S and Zhivotovsky B: Mitochondria as targets for cancer chemotherapy. Semin Cancer Biol 19: 57-66, 2009.

55. Leber B, Geng F, Kale J and Andrews DW: Drugs targeting Bcl-2 family members as an emerging strategy in cancer. Expert Rev Mol Med 12: e28, 2010

56. Indran IR, Tufo G, Pervaiz S and Brenner C: Recent advances in apoptosis, mitochondria and drug resistance in cancer cells. Biochim Biophys Acta 1807: 735-745, 2011.

57. Dijk SN, Protasoni M, Elpidorou M, Kroon AM and Taanman JW: Mitochondria as target to inhibit proliferation and induce apoptosis of cancer cells: The effects of doxycycline and gemcitabine. Sci Rep 10: 4363, 2020.

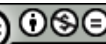

This work is licensed under a Creative Commons Attribution-NonCommercial-NoDerivatives 4.0 International (CC BY-NC-ND 4.0) License. 